\title{
Mosquito larval habitats and public health implications in Abeokuta, Ogun State, Nigeria
}

\author{
M.A. ADELEKE ${ }^{1 *}$, C.F. MAFIANA ${ }^{1}$, A.B. IDOWU' ${ }^{1}$, M.F. ADEKUNLE ${ }^{2}$ and S.O. SAM-WOBO ${ }^{1}$ \\ Department of Biological Sciences, University of Agriculture, P.M.B 2240, Abeokuta, Ogun State, Nigeria \\ 2. Department of Forestry and Wild life Management, University of Agriculture, P.M.B 2240, \\ Abeokuta, Ogun State, Nigeria
}

\begin{abstract}
The larval habitats of mosquitoes were investigated in Abeokuta, Nigeria in order to determine the breeding sites of the existing mosquito fauna and its possible public health implications on the residents of the City. The habitats were sampled between August 2005 and July 2006 using plastic dippers and a pipette. The habitats were grouped as ground pools/ponds, gutters/open drains, tyres, domestic containers and treeholes/ leaf axils. Ten species of mosquitoes were encountered in the five habitats namely Mansonia africana, M. uniformis, Culex quinquefasciatus, Aedes aegypti, Ae. albopictus, Ae. vittatus, Cx tigripes, Anopheles gambiae s.1., An. funestus and Eretmapodite clnysogaster. Ae. aegypti bred in all the habitats sampled while $C x$ quinquefasciatus bred in four habitats except tree holes/leaf axils. An. gambiae s.l and Ae. albopictus occurred in three habitats while other species bred only in one or two habitats. Ground pools and domestic containers recorded the highest number of species followed by gutters/open drains. Tree holes/leaf axils was the least preferred habitat with the lowest number of species occurrence. However, statistical analysis revealed non-significant difference in species occurrence in the five habitats. The availability of the habitats to support the breeding of Aedes, Culex and Anopheles, which are known vectors of urban yellow fever, lymphatic filariasis and malaria suggest that the residents of Abeokuta City are at risk of mosquito-borne diseases. It is important that residents of the City are enlighten on the environmental factors that contribute to mosquito breeding and that the Government should institute proper sanitation measures to reduce mosquito breeding sites.
\end{abstract}

Key words: mosquito vectors, larval habitats, Nigeria

\section{Introduction}

Mosquitoes are widely distributed throughout the world and they utilize different water bodies for their breeding (WHO, 1982). Many species breed in both natural and artificial containers such as pools, gutters, coconut shells, tree holes, bamboo stumps, leaf axils, septic tank and so on (Mafiana, 1989; Aigbodion \& Anyiwe, 2005). The distribution of mosquitoes is influenced both directly and indirectly by climatic and environmental factors (Mafiana et al., 1998). Mosquitoes prefer an environment with certain resources (food, shelter, breeding sites, favourable temperature and suitable humidity) in sufficient amount and at appropriate time for survival and development (Romoser $\&$ Stoffolano, 1998). The recent increase in ecological and environmental modification due to agricultural activities and urbanization has been observed to contribute to the breeding of various mosquito species (Amusan et al., 2005).

Studies to identify local mosquito species have been carried out in several parts of Nigeria including Ibadan, Lagos, Zaria and Benin (Okorie, 1973; Mafiana, 1989; Anyanwu et al., 1999; Aigbodion \& Odiachi, 2003). Though, attempt was made thirteen years ago to determine the breeding sites of mosquitoes in Abeokuta (Mafiana et al., 1998), the recent tremendous change in environmental conditions of the City as a result of urbanization underscores the need for current documentation of the mosquito fauna and their habitats. Constant studies on biology and larval ecology of mosquitoes have been observed as important tools in mosquito control. Such studies will help to determine the existing and disappearing mosquito species and the extent of their distribution (Mafiana et al., 1998; Anyanwu et al., 1999). This study was therefore designed to investigate the larval habitats of existing mosquito fauna and its possible public health implications on the residents of Abeokuta City, southwest, Nigeria.

\section{Materials and Methods}

This study was carried out in Abeokuta $\left(7^{\circ} 10^{\prime} \mathrm{N}\right.$, $\left.3^{\circ} 21^{\prime} \mathrm{E}\right)$ in the transitional zone between the tropical rainforest and derived savannah zone in the southwest, Nigeria. The area experiences two seasons, the dry season (November to March) and the wet season (April to October).

The larval sampling of all accessible breeding sites was carried out weekly in five stratified locations; Ago-Ika, Ijaye, Kugba, Ibara and Obantoko all within Abeokuta City between August 2005 and July 2006 to include both wet and dry seasons. These 
locations however represent different divisions in the City. The breeding sites sampled were categorized into five groups according to the similarity of the habitats. (i) Gutters /drains which include gutters, open drains, peridomestic run-offs from bathroom and soakaway; (ii) Ground pools which include rain water collection on the road, pool water around public taps, wells and abandoned ponds; (iii) Tyres; (iv) Domestic containers which include discarded pots, tanks, plastic rubbers, buckets, pure water nylon and aluminium containers; and (v) Tree holes/leaf axils which include banana leaf axils, pineapple leaf axils and tree holes.

The larvae in ground pools and gutters were collected with the aid of plastic dippers while pipette was used for the collection of larvae from tree holes. The sieve of about $0.55 \mathrm{~mm}$ mesh-size was used for the collection of larvae in domestic containers and tyres. All the larvae collected were stored in labelled specimen bottles for identification in the laboratory. The larvae were allowed to emerge into adult inside mosquito cage and later identified using keys described by Gillett (1972).

Analysis of variance was used to test for sig- nificant difference in species occurrence of mosquito species in the larval habitats.

\section{Results}

During the wet seasons (April-October) a total of 71 ground pools and 2 uncompleted ponds were sampled. An. gambiae sensu lato dominated other five species occurring 34 times $(46.58 \%)$ out of the 73 observations. Other species encountered were Ae. aegypti 14 (19.17\%), M. africana 6 (8.21), Cx quinquefasciatus 27 (36.98\%), Cx tigripes (1.36\%) and An. funestus $1(1.36 \%)$ In gutters/drains, a total of 132 observations were made and four species of mosquitoes were encountered. The larvae of $C x$ quinquefasciatus was the most abundant species occurring $78(59.09 \%)$ times followed by An. gambiae 41 (31.06\%). Other species were Ae. aegypti 6 (4.55\%) and Ae. albopictus 5 (5.30\%). Out of the 63 discarded tyres sampled, the larvae of Ae. albopictus were observed as most dominant species occurring 41 (65.07\%) times followed by Ae. aegypti 40 (63.49\%). Other species were $C x$ quinquefasciatus 3 (4.76\%)

Table 1: Larval habitats of mosquito species in the wet and dry season in Abeokuta

\begin{tabular}{|c|c|c|c|c|c|c|c|}
\hline \multirow[t]{2}{*}{ Habitats } & \multirow[t]{2}{*}{ Species } & \multicolumn{2}{|c|}{ Wet season } & \multicolumn{2}{|c|}{ Dry season } & \multicolumn{2}{|l|}{ Total } \\
\hline & & No & $(\%)$ occurrence & No & $\%$ & No & $\%$ \\
\hline \multirow[t]{6}{*}{ Ground pools } & An. gambiaes.I & 73 & 46.58 & 12 & 8.33 & 85 & 41.18 \\
\hline & Ae. aegypti & & 19.17 & & 0 & & 16.4 \\
\hline & M. africana & & 8.21 & & 0 & & 7.0 \\
\hline & Cx. quinquefasciatus & & 36.98 & & 25.0 & & 37.5 \\
\hline & An. funestus & & 1.36 & & 0 & & 1.18 \\
\hline & Cx. tigripes & & 1.36 & & 0 & & 1.18 \\
\hline \multirow[t]{4}{*}{ Gutters/drains } & Cx. quinquefasciatus & 132 & 59.09 & 15 & 80.0 & 147 & 61.22 \\
\hline & An. gambiae s.I & & 31.06 & & 20.0 & & 29.93 \\
\hline & Ae. aegypti & & 4.55 & & 33.3 & & 4.08 \\
\hline & Ae. albopictus & & 5.30 & & 0 & & 4.76 \\
\hline \multirow[t]{4}{*}{ Tyres } & Ae. vittatus & 63 & 1.58 & 7 & 0 & 67 & 1.49 \\
\hline & Ae. albopictus & & 65.07 & & 14.28 & & 64.17 \\
\hline & Ae. aegypti & & 63.49 & & 28.57 & & 61.19 \\
\hline & Cx. quinquefasciatus & & 5.30 & & 0 & & 4.4 \\
\hline \multirow{6}{*}{$\begin{array}{l}\text { Domestic } \\
\text { containers }\end{array}$} & Ae. aegypti & 122 & 45.90 & 14 & 57.14 & 136 & 47.06 \\
\hline & M. africana & & 0.81 & & 0 & & 0.74 \\
\hline & Ae. albopictus & & 15.57 & & 0.07 & & 14.71 \\
\hline & An. gambiae s.I & & 1.64 & & 14.28 & & 2.94 \\
\hline & Er. chrysogaster & & 0.81 & & 0 & & 2.21 \\
\hline & Cx. quinquefasciatus & & 3.28 & & 0 & & 2.94 \\
\hline $\begin{array}{l}\text { Tree holes/leaf } \\
\text { axils }\end{array}$ & Ae. aegypti & & 57.14 & 0 & 0 & 7 & 57.14 \\
\hline
\end{tabular}


and Ae. vittatus 1 (1.58\%). For domestic containers, a total of 122 observations were made, out of which Ae. aegypti occurred 56 times (45.90\%) followed by Ae. albopictus (15.57\%). Other species were found in the following proportions: An. gambiae 2 (1.64\%), M. africana 1 (0.81), Eretmapodite chrysogaster 1 $(0.81 \%)$ and $C x$ quinquefasciatus 4 (3.28). Five plant species were encountered with holes/leaf axils during the wet season survey. Two out of the five species were found to contain larvae of Ae. aegypti, the only species found in treeholes. One of the two tree holes of guava tree was found to harbour $50 \%$ while in 3 out of 5 tree holes of cashew tree the larvae of Ae. aegypti (60\%) were found (Table 1).

In the dry season, twelve ground pools were sampled and two mosquito species were encountered. The species encountered were $C x$ quinquefasciatus (25.00\%) and An gambiae (8.33\%). Three species of mosquitoes were encountered in 15 gutters/drains sampled. The species were $C x$ quinquefasciatus 12 (80\%), An. gambiae s.1. $3(20 \%)$ and M. uniformis 5 $(33.3 \%)$. The seven discarded tyres sampled during the dry season yielded the larvae of Ae. albopictus which occurred twice and Ae. aegypti which occurred once. The larvae of Ae. aegypti were also the most abundant species in domestic containers during the dry season, occurring 8 times $(57.14 \%)$ out of 14 observations. Other species found in this habitat were, An. gambiae s.1. $2(14.28 \%)$ and Ae. albopictus $1(0.07 \%)$. All the tree holes sampled during the dry season did not retain water.

When the data of both wet and dry seasons for all the breeding habitats were pooled, ground pools and domestic containers harboured the highest number of species (6) followed by gutters/drains (5). Tree holes/ leaf axils were the least utilized habitats (1). There was no significant difference in species occurrence in different habitats $(P>0.05)$.

\section{Discussion}

The presence of five genera of mosquitoes, Anopheles, Culex, Mansonia, Aedes and Eretmapodites were observed in the present study. Similar findings have been reported in previous studies on mosquito fauna in Nigeria (Okore, 1973; Aigbodion \& Odiachi, 2003). The breeding of mosquitoes was observed virtually in all habitats sampled. Ground pools, gutters, domestic containers and tyres constituted the most important breeding sites for mosquitoes. Earlier report on mosquito breeding sites in Abeokuta showed that tyres and domestic containers provide the highest number of breeding sites in both wet and dry seasons (Mafiana et al., 1998). The intense breeding of mosquitoes was also observed in tyres and domestic containers in both seasons during this study. By contrast, gutters were described as short period breeding sites, this was not the situation in the present study. Gutters were seen in both seasons with high number of mosquito species. The poor sanitation of Abeokuta appears to be responsible for this. Most of the gutters have been blocked with refuse and sewage, therefore rendering the water stagnant. This consequently enhances the breeding of different mosquito species. According to Mafiana et al., (1998), tree holes/leaf axils can only retain water for short period of time and dry up at the time of no rain. This may be the reason to explain the low contribution of tree holes/leaf axils to the breeding of mosquitoes in this study.

Ae. aegypti bred in all the breeding sites including tree holes. This indiscriminate breeding habit has long been reported by Okorie (1970), Mafiana et al. (1998) and Adeleke (2003). The high occurrence of Ae. albopictus in discarded tyres could probably be due to its adaptable life to this habitat. The widespread of Ae. albopictus in Nigeria has been receiving attentions since early 1990s when its presence was first observed in some rural areas in Delta State. Ae. albopictus is a native of South-Asia countries where it has been known as efficient vector of yellow fever and dengue. The vector was imported to Nigeria through second hand tyres (Mbanugo \& Okpalaonuju, 2003). As a result, the preponderance of Ae.albopictus is being speculated to be occurring in cities where tyre business booms or where improper management of used tyres is being practiced. During this study, tyres were seen in many residential areas with no specific function, and in few cases, they were either used for erosion control or plant guide. Both Ae. aegypti and Ae. albopictus have been implicated in the transmission of yellow fever and other arboviruses. Though, yellow fever epidemics have not been reported recently in Abeokuta, the outbreak of the disease had been reported in neighbouring States (Mbanugo \& Opkalaonuju, 2003). Owing to the epidemiological implications of these behaviours and having considered Ogun State as a borderline with Benin Republic, the need for public health education cannot be over-emphasized.

The breeding of $C x$ quinquefasciatus was observed in all the habitats except tree holes while An. gambiae bred in three habitats except tyres and tree holes. The large occurrence of $C x$. quinquefasciatus in gutters is not surprising because of its preference for polluted water (Mafiana, 1989). The high occurrence of An. gambiae s.1. in gutters after Cx quinquefasciatus is however remarkable and shows that An. gambiae 
can utilize other habitats apart from ground pool in which it has been known for. The frequent occurrence of this species in most of the gutters would probably worsen the malaria episode in Abeokuta as the city had been reported as a malaria hyperendemic area (Ojo \& Mafiana, 2001). Though, its presence was only observed in clean or semi-polluted water in the gutters, regular draining of gutters within Abeokuta will be the most effective way to reverse the situation. Meanwhile, the prevalence of bancroftian filariasis has not been documented in Ogun State but the infective larvae of the parasite had been found in An gambiae, Cx quinquefasciatus, M. uniformis, Ae. Aegypti and Ae. albopictus in some suburbs of Abeokuta (Amusan, 2004). Incidentally, these species were encountered in substantial number in most of the breeding sites. Considering the rapid rate of development in Abeokuta and increasing level of rural-urban drill, the residents of Abeokuta are therefore at risk of bancroftian filariasis.

$C x$ decens and $C x$ andersoni that were earlier reported in Abeokuta (Mafiana et al., 1998) were not encountered in the present study. The absence of these species may not be unconnected to the lack of suitable breeding sites. The widespread use of organochlorine insecticides and various detergent products to which Cx quinquefasciatus appears less susceptible, eliminate other Culex species (Anyanwu et al., 1999). It could also be as a result of other environmental factors not known to this study. M. africana, M. uniformis, Ae. vittatus, Aedes albopictus and An .funestus were encountered in addition to seven species earlier documented in Abeokuta. The poor sanitation and rapid development projects could be responsible for the appearance of these species as most of them were encountered in gutters, tyres, and domestic containers.

In conclusion, this study has provided information on larval habitats of mosquitoes in Abeokuta and the contribution of urbanization to the appearance of species earlier thought to be absent in the City. Since most of the species encountered are potential vectors of one mosquito-borne disease or the other of which their high prevalence has been reported in the City or its neighbouring towns, we therefore recommend that the residents of Abeokuta be enlightened on the environmental factors that contribute to mosquito breeding. Ogun State Government should also embrace proper environmental sanitation so as to reduce the breeding sites of mosquitoes.

\section{Acknowledgements}

The Authors thank Messrs A.O. Adeyi, Q. Junaid, O. J. Funmilola and S.O. Bankole for their assistance in field collection of mosquito larvae. The technical assistance of the Late Dr. A.A.S Amusan is greatly acknowledged.

Received 15 November 2007

Revised 27 March 2008

Accepted 29 March 2008

\section{References}

Adeleke, M.A. (2003) Mosquito species breeding in artificial containers in Ikenne farm settlement, Ogun State, Nigeria. BSc Dissertation, University of Agriculture, Abeokuta 35pp

Aigbodion, F.I. \& Anyiwe, M.A. (2005) Mosquitoes and the environments: some economic costs of malaria in Nigeria. Nigerian Journal of Entomology 22, 93-107.

Aigbodion, F.I. \& Odiachi, F.C. (2003) Breeding sites preferences of Anopheline mosquitoes in Benin City Nigeria. Nigerian Journal of Entomology 20, 1-7.

Amusan, A.A.S., Mafiana, C.F., Idowu, A.B. \& Olatunde, G.O (2005) Sampling mosquitoes with CDC light traps in rice field and plantation communities in Ogun State, Nigeria. Tanzania Health Research Bulletin 7, 111-116.

Amusan, A.A.S. (2004) Distribution of mosquitoes (Diptera: Culicidae) and Disease Transmission Patterns in Ogun State. PhD Thesis, University of Agriculture, Abeokuta, Ogun State $\mathrm{pp} 336$.

Anyanwu, I.W., Agbede, R.I.S., Ajanusi, O.J. \& Umoh, J.U. (1999) A survey of culicids (mosquitoes) in a northern Guinea savannah town of Zaria, Kaduna State. Nigerian Journal of Parasitology 20, 137-148.

Gillett, J.D. (1972) Common African Mosquitoes and their Medical Importance. William Heinemann Medical Books Ltd; London, pp 236.

Mafiana, C.F. (1989) Observation of mosquito species breeding in open drains and test containers in Lagos Nigeria. Bioscience Research Communications 1, 95-102.

Mafiana, C.F., Anaeme, L. \& Olatunde, G.O. (1998) Breeding sites of larval mosquitoes in Abeokuta, Nigeria. Nigerian Journal of Entomology $15,136-143$. 
Mbanugo, J.I. \& Okpalononuju, C.N. (2003) Surveillance of mosquito vectors in some habitats of Akwa Metropolis, Anambra, Nigeria. Nigerian Journal of Parasitology 24, 185-190.

Okorie, T.G. (1970) The breeding site preference of mosquitoes in Ibadan, Nigeria. Nigerian Journal of Entomology 1, 71-80.

Okorie, T.G. (1973) Studies on the Ecology of Mosquitoes in Ibadan with Special Reference to Mansonia africana (Theobold). MSc. Thesis, University of Ibadan, Ibadan.
Ojo, D.A. \& Mafiana, C.F. (2001) Evaluation of fever in the presumptive diagnosis of malaria endemicity. Nigerian Journal of Parasitology 22, 35-42.

Romoser, B. \& Stofollano, R.S. (1998) The Science of Entomology. MCGrew Hall, London pp 328.

WHO (1982) Manual on Environmental Management for Mosquito Control with special emphasis in Malaria Vectors. Who Offset Publication $66,140-148$. 